\title{
Esterification of levulinic acid into ethyl levulinate catalysed by sulfonated hydrothermal carbons
}

\author{
Filoklis D. Pileidis, Maham Tabassum, Sam Coutts, Maria-Magdalena Titirici* \\ Queen Mary University of London, School of Engineering and Materials Science, Mile End Road, E1 4NS, London, United Kingdom
}

\section{A R T I C L E I N F O}

Article history:

Received 11 April 2014

Accepted 30 April 2014

Published 20 June 2014

\section{Keywords:}

Sulfonated hydrothermal carbons

Glucose

Cellulose

Rye straw

Esterification

Levulinic acid

Ethyl levulinate

\begin{abstract}
A B S T R A C T
The synthesis of carbon-based, heterogeneous sulphonic catalysts for the production of levulinate esters. Hydrothermal treatment at moderated temperatures was employed to generate highly functional carbonaceous materials, referred to as hydrothermal carbons (HTCs), from both glucose, cellulose and rye straw. The products were sulfonated to generate solid acid-catalysts. Characterisation of the as-synthesised materials as well as catalyst activity tests were performed. SEM images indicate the micrometre-sized particles present in both HTCs were largely unaffected by sulfonation, although cellulose-derived HTC displayed signs of inadequate hydrolysis. FT-IR spectroscopy and elemental analysis confirmed successful incorporation of sulphonic groups. ${ }^{13} \mathrm{C}$ solid state NMR, in addition to TGA, elucidated the carbons' structural composition and supported the commonly-proposed hydrothermal carbonisation mechanism. Finally, the catalysts were tested via levulinic acid-ethanol esterification and gave high conversion and ester-selectivities (> 90\%).
\end{abstract}

(C) 2014, Dalian Institute of Chemical Physics, Chinese Academy of Sciences. Published by Elsevier B.V. All rights reserved.

\section{Introduction}

Homogeneous-acid catalysts, such as sulphuric acid, have been recently used to produce biodiesel fuels. Although the homogeneous esterification of acids has been reported to give better conversion compared to heterogeneous esterification system, it is well-known that the use of mineral acids has some significant disadvantages associated with the handling, equipment corrosion due to their miscibility with the reaction medium, separation problems, disposal and regeneration due to their toxic and corrosive nature. The genesis of the green chemistry principles and increasing concerns about environmental issues, have stimulated the research for recyclable strong solid acids to replace of conventional toxic and corrosive acid catalysts [1].

Levulinate esters including ethyl, methyl, or butyl levulinate are the esterification products of levulinic acid and they have numerous potential applications in the flavouring and fragrance industry or as a blending component in biodiesel [2-4]. Biodiesel fuel has many favourable properties as a possible renewable extender for petroleum diesel fuel [2]. In addition to its renewability, other advantages of biodiesel include biodegradability, miscibility with petroleum diesel, increased lubricity, high flash point, and reduced emissions of particulate matter, unburned hydrocarbons, and CO during fully warmed-up conditions [3]. On the other hand, some of the known problems with biodiesel fuel include thermal and oxidative instability, poor low temperature flow properties (higher cloud point), increase in $\mathrm{NO}_{x}$ emissions, increased fuel consumption due to lower net heat of combustion, and increased unburned fuel and CO emission [4]. Levulinate esters are suitable as additives to biodiesel transportation fuels with excellent properties, such as low toxicity, high lubricity, flashpoint stability, and moderate flow properties under low temperature conditions [5].

\footnotetext{
*Corresponding author. Tel: +44 -20-7882 6272; E-mail: m.m.titirici@qmul.ac.uk DOI: 10.1016/S1872-2067(14)60125-X | http://www.sciencedirect.com/science/journal/18722067 | Chin. J. Catal., Vol. 35, No. 6, June 2014
} 
The most applied method for the reaction of levulinic acid (LA) with alcohols to produce esters is in the presence of a homogeneous mineral acid or a heterogeneous catalyst. The esterification reaction can proceed in the presence but also in the absence of a catalyst. Uncatalysed reactions have been reported as a possible way for esters production, but the reaction rate is very slow, depending on the catalysis of carboxylic acid itself [6]. Bankole et al. [6] reported the uncatalysed esterification of various acids including levulinic acid to ethyl levulinate (levulinic acid:ethanol $1: 1$ ) at $25-250{ }^{\circ} \mathrm{C}$. The highest conversion was achieved at $250{ }^{\circ} \mathrm{C}$ after $60 \mathrm{~min}(60 \%$ levulinic acid conversion), whereas the equilibrium was only $21 \%$ at $60{ }^{\circ} \mathrm{C}$ after $120 \mathrm{~h}$ reaction time. Levulinate esters were mainly produced from LA in the presence of mineral acids, which lead to a high yield of corresponding products [7-9].

Dharne et al. [10] studied esterification of levulinic acid to $n$-butyl levulinate over a heteropolyacid supported on acid-treated clay. An optimized $n$-butyl levulinate yield of $97 \%$ was achieved by using a catalyst of $20 \%$ dodecatungestophosphoric acid (DTPA) supported on K10. Methyl and ethyl levulinate were also synthesised in the presence of Keggin Unit-SiO 2 [11] catalysts, achieving a methyl levulinate yield of $73 \%$ and an ethyl levulinate yield of $68 \%$. Silica-included Wells-Dawson heteropolyacid catalysts were explored for the synthesis of ethyl levulinate, analysis of the catalyst recycling experiments revealed that the 40WD-S catalyst exhibited excellent catalytic activity, although the product yield declined from $72 \%$ to $68 \%$ during three reaction cycles [12].

Sulfonated carbonaceous materials have been synthesized and investigated as environmentally benign, cheap, and recyclable catalysts for the production of biodiesel via the esterification of fatty acids. Budarin et al. [13] synthesized a sulfonated Starbon 400 with $0.5 \mathrm{mmol} / \mathrm{g} \mathrm{SO}_{3} \mathrm{H}$ loading. Sulfonated glucose microspheres (2-3 mm) were also synthesized (sulfur 0.57 $\mathrm{mmol} / \mathrm{g}$ ) by Fuertes et al. [14] and have been used for the esterification of oleic acid into of ethyl oleate. Wang et al. [15] also synthesized glucose-based catalysts by using $p$-toluenesulfonic acid as sulfur reagent, for the esterification of succinic acid with ethanol. The sulfur content of these materials was measured at $1.27 \mathrm{mmol} / \mathrm{g}$.

However, to the best of our knowledge, biomass-derived carbon materials have not been yet employed as heterogeneous catalysts for the esterification of levulinic acid to levulinate esters. Especially important are in this respect the hydrothermal carbon (HTC) materials as they are prepared from biomass precursors under mild conditions $\left(180-280{ }^{\circ} \mathrm{C}\right)$ [16]. Due to these mild reaction conditions they have hydrophilic surfaces with oxygenated surface groups such as $-\mathrm{OH}$ or $-\mathrm{COOH}$. These groups already confer them an acidic character but it also allows their further modification with other functionalities [17]. Our group has already demonstrated the great potential of HTC materials as heterogeneous catalysts for various reactions where the hydrophilic character and the polar groups of these materials play a very important role [18]. Here we demonstrate for the first time the potential of sulfonated HTC materials to act as efficient heterogeneous acid catalysts for the conversion of levulinic acid into ethyl levulinate.
This is a proof of concept study where we have used commercially available levulinic acid. However, during the hydrothermal carbonization of various biomass precursors, important amounts of levulinic acid are detected in the liquid phase. The amount depends on the reaction conditions (i.e. precursor concentration, catalysts, temperature, time, etc.). Therefore, in the future we would like to use the biomass-derived HTC materials as heterogeneous catalysts for converting the "in situ" formed levulinic acid in the liquid phase in other important chemicals such as ethyl levulinates but also others.

\section{Experimental}

\subsection{Synthesis}

\subsubsection{Synthesis of HTC Carbons}

Various concentrations of biomass precursors (i.e. glucose, cellulose, rye straw) are added to $30 \mathrm{~mL}$ stainless steel autoclaves equipped with a Teflon inlet with or without $\mathrm{HCl}$ as catalyst. The autoclaves are then heated in an oven at $230{ }^{\circ} \mathrm{C}$ for $24 \mathrm{~h}$. After the hydrothermal reaction, the samples (solid + liquid) are removed from the autoclave and centrifuged at a speed of $1400 \mathrm{rpm}$ in order to separate the liquid from the solid phase. The solid phase is washed with ethanol and dried in a vacuum oven at $80{ }^{\circ} \mathrm{C}$ for $48 \mathrm{~h}$ prior to further characterisation and further use. The remaining liquid phase is filtered and stored in the fridge until further analysis. For the production of sulfonated HTC carbons, only the no acid catalysts (no $\mathrm{HCl}$ )produced HTC materials will be used.

\subsubsection{Synthesis of HTC-S Carbons}

The as-produced HTC materials are treated with sulphuric acid. The purpose of this step is to functionalise these materials with $-\mathrm{SO}_{3} \mathrm{H}$ groups and increase their acidity. The HTC materials are suspended in $\mathrm{H}_{2} \mathrm{SO}_{4}$ (99.999\% purity, $10 \mathrm{~mL}$ acid per $\mathrm{g}$ of HTC material) and heated for $4 \mathrm{~h}$ at $80{ }^{\circ} \mathrm{C}$ [14]. After sulfonation, the solid materials are gently stirred overnight in $500 \mathrm{~mL}$ of water to remove all the unreacted sulphuric acid. Then, they are washed with distilled water until the $\mathrm{pH}$ of the supernatant is close to 7, and finally with ethanol. The materials are dried in a vacuum oven overnight at $60^{\circ} \mathrm{C}$, before being characterised and tested as catalysts in the esterification reactions. From now on, the sulfonated material will be referred as HTC-Precursor-S (e.g. HTC-Cell-S for cellulose, HTC-Glu-S for glucose and HTC-RS-S for rye straw).

\subsection{Characterisation}

Elemental composition was determined using a Vario El elemental analyzer. Scanning electron microscopy (SEM) was carried out on a FEI Quanta 3D Environmental SEM (ESEM) to observe the surface morphology of all samples. The samples were mounted on aluminium stubs and coated with gold prior to analysis.

For an initial detection of successful sulphonation and identification of functional groups, FT-IR spectra were acquired for all samples. The spectra were recorded on a Bruker Tensor-27 
spectrometer (range 4000 to $400 \mathrm{~cm}^{-1}$; scans 32), geared with a liquid nitrogen-cooled Mercury Cadmium Telluride (MCT) detector.

Specific structures found in the sulphonated materials were studied via a Bruker Avance $300 \mathrm{MHz}$ spectrometer, operated at a Magic-angle spinning (MAS) rate of $14 \mathrm{kHz}$. For rotation, 4 $\mathrm{mm}$ zirconia sample holders were used.

In order to gain further structural insight, all of the samples were subjected to thermogravimetric treatment in a TGA Q500 machine (TA instruments). Approximately $3 \mathrm{mg}$ of each carbonaceous powder was used. The temperature was raised up to $60{ }^{\circ} \mathrm{C}$ under air, and then from 60 to $1000{ }^{\circ} \mathrm{C}$ under nitrogen, at a constant rate of $10^{\circ} \mathrm{C} / \mathrm{min}$.

$\mathrm{CO}_{2}$ physisorption analysis (for surface area/porosity) was conducted in Germany on a Quadrasorb SI-MP analyser (Quantachrome instruments) at $0{ }^{\circ} \mathrm{C}$. The sample was prepared by degassing at $150{ }^{\circ} \mathrm{C}$ for $20 \mathrm{~h}$, and QuadraWin 5.05 software was employed for data analysis.

\subsection{Esterification of LA into Ethyl Levulinate catalysed by HTC-S Carbons}

Commercially available levulinic acid is used as a model compound in order to produce levulinate esters. Levulinic acid is reacted with ethanol (EtOH/Acid ratio 5:1 mmol) for 1 and 3 $\mathrm{h}$ at $60^{\circ} \mathrm{C}$ and at room temperature under stirring in the presence of sulphuric acid (catalyst amount: $5 \mathrm{wt} \%$ of LA) as homogenous catalysts, the HTC-S heterogeneous catalysts or no catalyst at all (catalyst amount: $5 \mathrm{wt} \%$ of LA). The quantification of Ethyl levulinate and of unreacted levulinic acid was done by using GC-MS.

\subsection{Analysis}

Qualitative and quantitative analysis of the esterification product mixture (with a focus on ethyl levulinate yield) was performed using gas chromatography-mass spectrometry (GC-MS) technique. Since the sample already contained un-reacted ethanol (the solvent usually employed in GC-MS), the mixture was directly placed onto the autosampler and subsequently analysed. A 6890N GC with Mass Selective Detector (MSD) 5973N (quadrupole) was used with the following conditions. Column dimensions: length $30 \mathrm{~m}$, internal diameter 0.25 $\mathrm{mm}$, film thickness $0.25 \mu \mathrm{m}$; split ratio 25:1; carrier gas Helium; temperature held at $40{ }^{\circ} \mathrm{C}$ for $5 \mathrm{~min}$, raised to $300^{\circ} \mathrm{C}$ at a rate of $20^{\circ} \mathrm{C} / \mathrm{min}$, and again maintained at the final temperature for 5 $\min$.

\section{Results and discussion}

\subsection{Morphology}

Figure 1 shows the SEM micrographs of glucose and cellulose-derived HTC micrographs before and after sulfonation. As previously reported, hydrothermal carbonization of glucose leads to a spherical morphology with agglomerated particles of around 1-2 $\mu \mathrm{m}$ (Fig. 1(a)). This is related to the fact that glucose

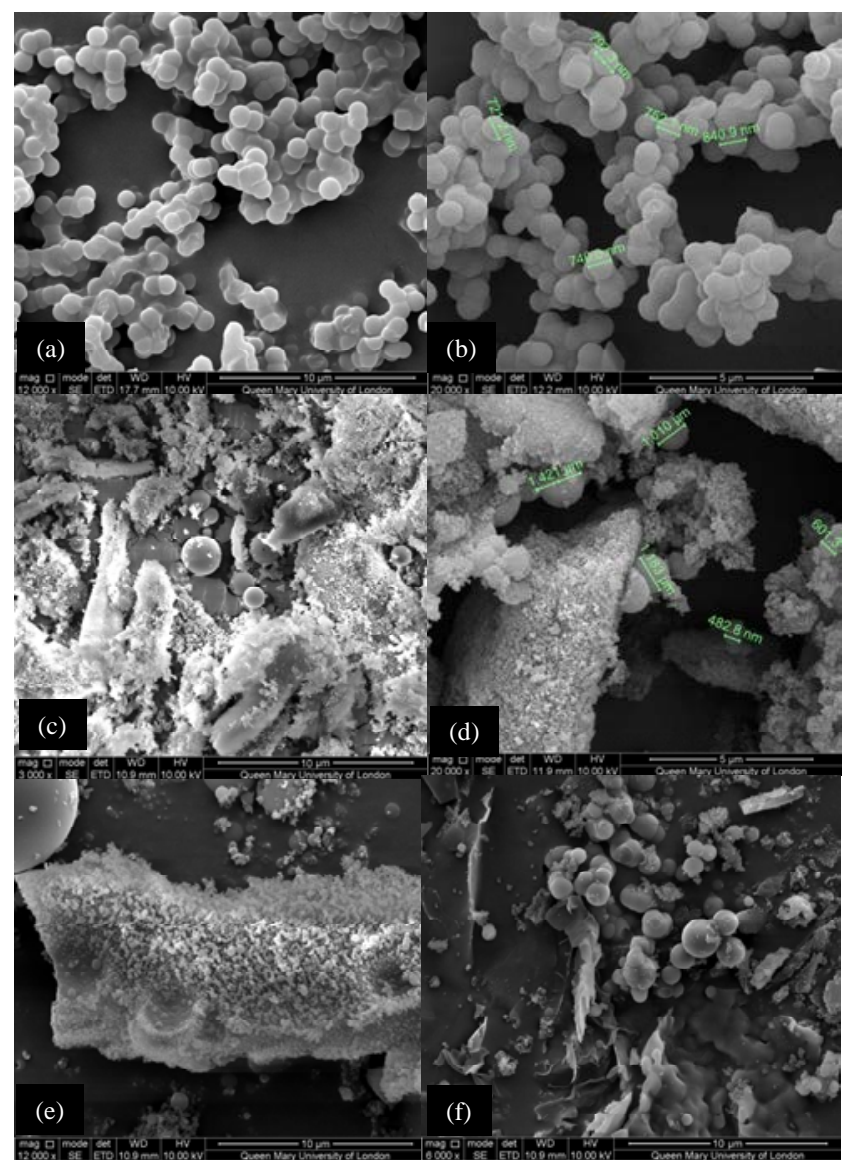

Fig. 1. SEM pictures of HTC glucose (a), sulfonated HTC glucose (b), HTC cellulose (c), sulfonated HTC cellulose (d), HTC rye straw (e), and sulfonated HTC rye straw (f).

is soluble in water and therefore the spheres form via a homogenous nucleation-growth mechanism from 5-hydroxymethylfurfural (HMF) as main "monomer" and a cascade of chemical reactions involving cyclo-additions, ring-opening reactions, substitutions, and polycondensations [19].

The situation is more complex in the case of cellulose. Cellulose is very stable to hydrolysis conditions even under sub-critical conditions due to the strong hydrogen bonding between the cellulose chains as well as $\beta(1 \rightarrow 4)$ glycosidic linkage. During the hydrothermal carbonization of cellulose, only parts of the cellulose structure can be hydrolysed to glucose and re-precipitated as HTC spheres via the HMF route. The insoluble parts undergo a "melting-reprecipitation" mechanism, which is more characteristic to classical pyrolysis. The dissolved glucose forms HTC via the HMF route, which can be then heterogeneously nucleate on the remaining cellulose crystalline units. For more details, the HTC mechanism from microcrystalline cellulose has been discussed in detail elsewhere [20]. Clearly the morphology of cellulose-derived HTC materials is a mixture of very small particles $(\approx 50 \mathrm{~nm})$, some micrometer particles as for glucose and some unreacted cellulose fragments. (Fig. 1(c)). In the case of using real lignocellulosic biomass (i.e. rye straw) the situation is even more complex than cellulose because of the presence of lignin, which cannot be converted by hydrothermal carbonization. Thus, lignin holds 
Table 1

Elemental composition of the HTC materials before and after sulfonation.

\begin{tabular}{|c|c|c|c|c|c|c|c|c|}
\hline \multirow{2}{*}{ Material } & \multicolumn{4}{|c|}{ Before sulfonation (\%) } & \multicolumn{4}{|c|}{ After sulfonation (\%) } \\
\hline & $\mathrm{H}$ & $\mathrm{C}$ & S & $0 *$ & $\mathrm{H}$ & $\mathrm{C}$ & S & $0 *$ \\
\hline Cellulose & 5.76 & 76.3 & 0 & 17.94 & 4.350 & 62.09 & 6.462 & 27.098 \\
\hline Glucose & 6.15 & 80.33 & 0 & 13.52 & 4.162 & 62.98 & 6.252 & 26.606 \\
\hline Rye straw & 4.96 & 69.72 & 0 & 25.32 & 4.142 & 65.02 & 5.107 & 25.731 \\
\hline
\end{tabular}

* The oxygen content was calculated by difference form $100 \%$ considering the other measured elements.

in place the fibrous structure characteristic for lignocellulosic biomass, while the hemicellulose and the partially hydrolysed cellulose for some HTC spheres on the surface of lignin-stabilised fibbers (Fig. 1(e)). After modification with sulphonic groups there are no major changes in the morphology of the HTC structures. Glucose-derived HTC material shows the exact same morphology after sulfonation, with agglomerated spheres of around $1 \mu \mathrm{m}$ (Fig. 1(b)). In the case of cellulose (Fig. 1(d)) and rye straw (Fig. 1(f)), the presence of sulphuric acid has also led to some minor morphological changes presumably due to additional dehydration-carbonization of the unreacted cellulose precursor [21].

\subsection{Chemical structure}

The elemental composition of the HTC materials before and after sulfonation is given in Table 1 . The $\mathrm{C}, \mathrm{H}$, and $\mathrm{O}$ contents of the HTC derived materials from glucose, cellulose, and rye straw are in good agreement with previous experiments [20]. The successful modification with sulfonic groups is here qualitatively confirmed by S content between 5-6.4 wt\%. While glucose and cellulose HTC materials have similar amounts of $\mathrm{S}$ after sulphonation, in the case of rye straw this is slightly lower (5\%) presumably due to the presence of lignin and the heterogenous distribution of polar groups in this material.

The FT-IR spectra of glucose derived HTC materials are shown in Fig. 2. The chemical nature of the functional groups bonded to the HTC and $\mathrm{HTC}_{-} \mathrm{SO}_{3}$ samples was further examined by a clear reduction of the intensity of the bands at $1700 \mathrm{~cm}^{-1}$, corresponding to $\mathrm{C}=0$ groups, can be seen, and the peak cen-

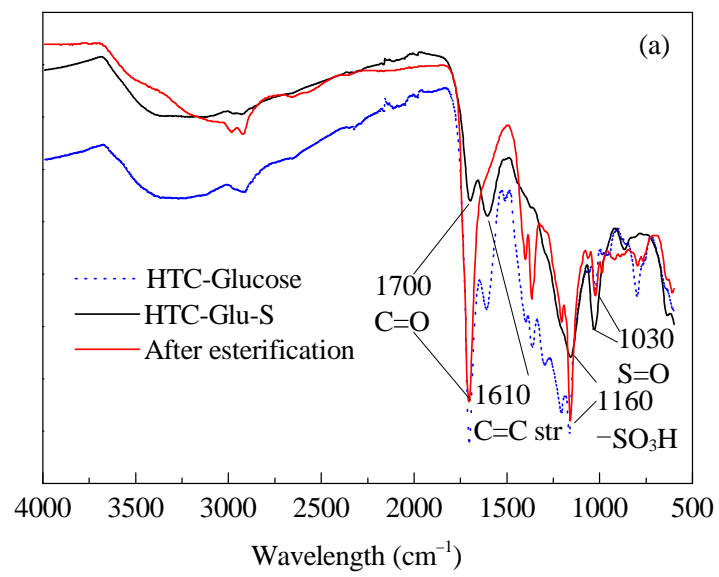

tered at around $2900 \mathrm{~cm}^{-1}$, which can be attributed to the stretching vibrations of aliphatic $\mathrm{C}-\mathrm{H}$, almost disappears. The FT-IR spectra of both $\mathrm{HTC}^{-\mathrm{SO}_{3}}$ samples (cellulose and glucose) reveal the presence of $-\mathrm{SO}_{3} \mathrm{H}$ groups: the sharp peak at 1025-1030 and 1160-1170 $\mathrm{cm}^{-1}$ are associated to symmetric $\mathrm{O}=\mathrm{S}=0$ stretching vibrations and to sulfonic groups [22], respectively. This indicates that the $\mathrm{SO}_{3} \mathrm{H}$ groups were successfully incorporated into the carbon framework by adding $\mathrm{H}_{2} \mathrm{SO}_{4}$ in the synthesis system. Both spectra show other bands that can be assigned to $\mathrm{C}=0$ stretching $\left(1700 \mathrm{~cm}^{-1}\right)$ and $\mathrm{C}=\mathrm{C}$ stretching $\left(1610 \mathrm{~cm}^{-1}\right)$. The situation is similar for the rye straw samples (result not shown), where we could clearly distinguish the peaks at $1025-1030$ and $1160-1170 \mathrm{~cm}^{-1}$, associated to symmetric $\mathrm{O}=\mathrm{S}=\mathrm{O}$ stretching vibrations and to sulfonic groups, respectively.

Figure 3 shows the solid state NMR spectra of the HTC materials after sulfonation. The solid state NMR characterisation was intensively carried out previously in our group [20]. Due to the quite large hydrogen content (Table 1), hydrothermal carbons can be analyzed by NMR spectra in solid state using the cross-polarization technique (13C-CP-MAS-NMR). Three distinct zones can be observed in the spectrum. The 0-60 ppm zone is typical for $\mathrm{sp}^{3}$ (aliphatic) carbons; the 100-160 ppm zone corresponds to $\mathrm{sp}^{2}$ (aromatic and olefinic) carbons, and it can be divided into two wide bands, one in the normal interval of $100-140 \mathrm{ppm}$ due to $\mathrm{C}=\mathrm{C}-\mathrm{C}$ atoms and another one at 140-160 ppm, typical for $\mathrm{C}=\mathrm{C}-\mathrm{O}$ in an aromatic structure (furans ring); finally, the peak at $200 \mathrm{ppm}$ can be attributed to carbonyl groups. The shoulder at around $60 \mathrm{ppm}$ is due to unreacted carbohydrate (i.e glucose) while in the case of rye straw the peak at around $40 \mathrm{ppm}$ is due to unreacted lignin present in rye straw. Simple sulfonation should not significantly modify this spectrum. However we can observe an increasing importance of the aromatic bands due to potential aromatization of partially saturated furan or benzene ring There is also a slight decrease in the functional groups due to potential oxidation of hydroxyl groups and $\mathrm{C}=0$ groups. In general, all those types of reactions can be explained by either the strong acidic character of the sulfonation medium or the oxidant behavior of sulfuric acid, and they would account for the decrease in hy-

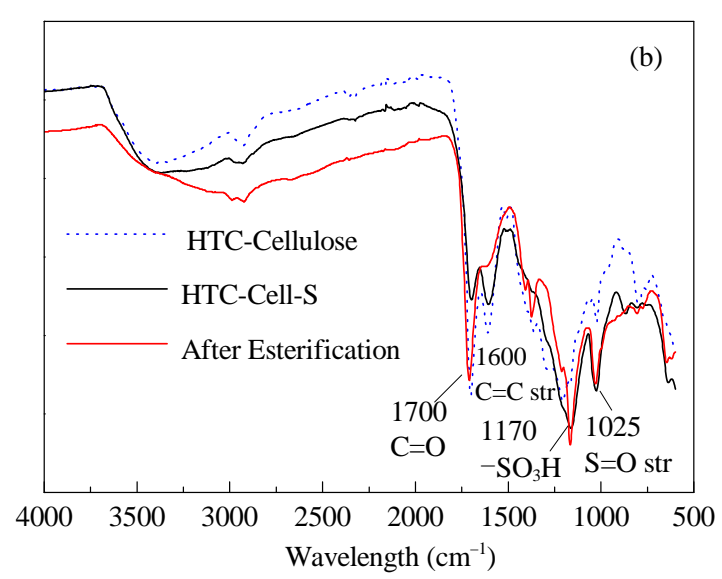

Fig. 2. FT-IR spectra of glucose derived HTC materials (a) before and after sulfonation, and cellulose-derived HTC materials (b) before (dot line), after sulfonation (black line) and after esterification (60 min) (red line). 


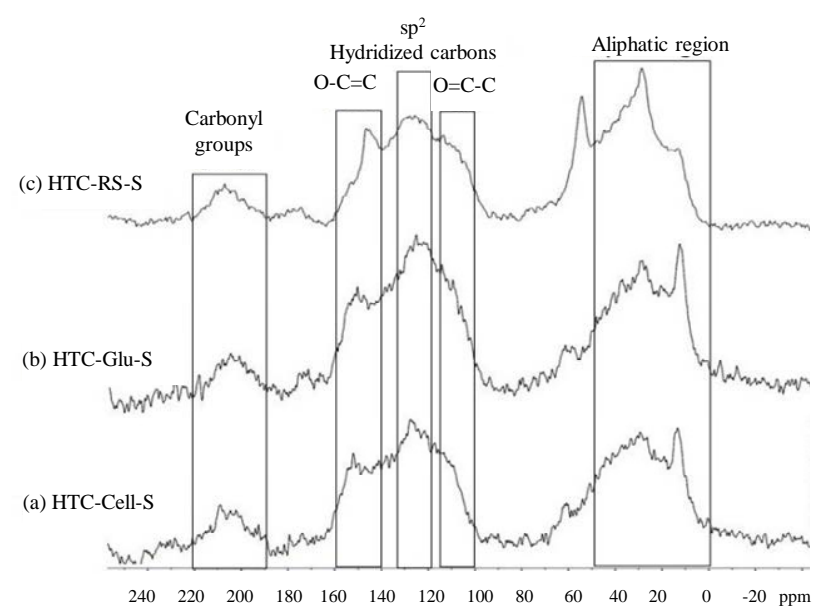

Fig. 3. Solid state ${ }^{13} \mathrm{C}$ CP NMR spectra of hydrothermal sulfonated carbon obtained from cellulose (a), glucose (b), and rye straw (c).

drogen content and the increase in oxygen content (Table 1). The lack of bands corresponding to carbonyl groups seems to indicate that they participate in the side reactions, for example the alkylation of aromatics, and hence the high oxygen content must be due to phenol and ether groups, in addition to the furan rings.

Unfortunately, at this stage of the experiments we do not have any quantitative data on the amount of sulfonic groups present on the surface of our HTC materials. We plan in the near future some quantitative titration experiments to clearly distinguish between various functionalities present on the HTC surface (i.e. $-\mathrm{COOH}$ versus $-\mathrm{H}_{2} \mathrm{SO}_{4}$ ) in order to understand their importance in the catalytic reactions.

Figure 4 shows TGA results under $\mathrm{N}_{2}$ of parent HTC materials (selected here only for glucose and cellulose). TGA profile of pure HTC materials before sulfonation show about 20\% weight loss of the sample weight at around $200{ }^{\circ} \mathrm{C}$, which corresponded to the loss of functional groups ( $-\mathrm{OH}$ mainly and some $-\mathrm{COOH})$. There is another significant weight loss between $450-600{ }^{\circ} \mathrm{C}$ due to re-organization of the carbon structure and further condensation into a more aromatic conductive structure. Compared to the parent HTC materials, the sulfonated materials clearly show an additional peak in the DTG cure at about $400{ }^{\circ} \mathrm{C}$ of about $10 \%$ for both glucose and cellulose clearly indicating the decomposition of the sulfonic acid groups in the sulfonated materials. In addition, there was no significant change in the weight of the sulfonated catalyst at $180{ }^{\circ} \mathrm{C}$. This observation suggested that our sulfonated catalyst should be stable for the esterification with levulinic acid at $180^{\circ} \mathrm{C}$ as used in the present study. It is also important to notice the clear shift towards higher temperatures in the DTG curve for the peak corresponding to the decomposition of the functional groups $(-\mathrm{OH},-\mathrm{C}=\mathrm{O},-\mathrm{COOH})$ on the sulfonated materials. This is in good agreement with the NMR data, where due to the strong acidic character of sulphuric acid (i.e. functional groups can take part in side reactions). In this study, direct quantification of the degree of sulfonic acid functionalization based on TGA results would subject to significant error, as sharp weight difference could not be measured. A very gradual weight low was generally observed and the temperature at which the decomposition ended could not be clearly seen. This measurement was further complicated due to small difference in the degree of functional groups between the samples.

It is known that the surface area and pore size are of upmost importance in heterogeneous catalysis as it facilitates the diffusion of the reagent to the active site. The adsorption isotherms and pore size distributions of glucose and cellulose after sulfonation are shown in Fig. 5(a) and (b). $\mathrm{N}_{2}$ adsorption is not a suitable method to measure the porosity due to their small pore size and soft polymer-like structure. In this case, due to kinetic restrictions these materials could not achieve equilibrium in an acceptable measurement time. This can clearly be observed from the open isotherms with negative adsorptions. Therefore, the BET values obtained from these measurements are not corresponding to the real values. The measurements were repeated several times after various degassing times and temperatures to make sure all the impurities were eliminated. The quantity of adsorbent was $300 \mathrm{mg}$. The $\mathrm{N}_{2}$ adsorption isotherms indicate non-porous materials. The pore size distributions obtained applying the NLDFT method to the adsorption isotherms indicate very low pore volumes $(\sim 0.4 \mathrm{~mL} / \mathrm{g})$ with pore size below $1 \mathrm{~nm}$. The adsorption isotherms of the materi-
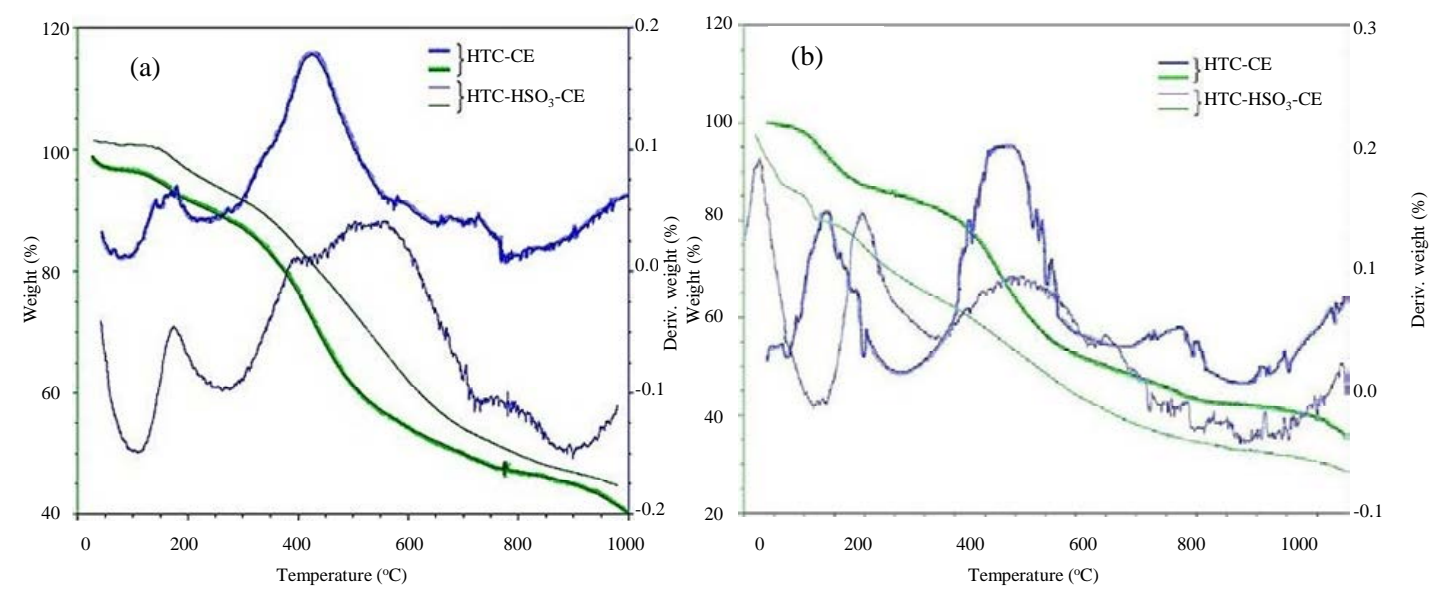

Fig. 4. TGA results for cellulose (a) and glucose-derived (b) HTC: before sulphonation (bold) and after (normal). 

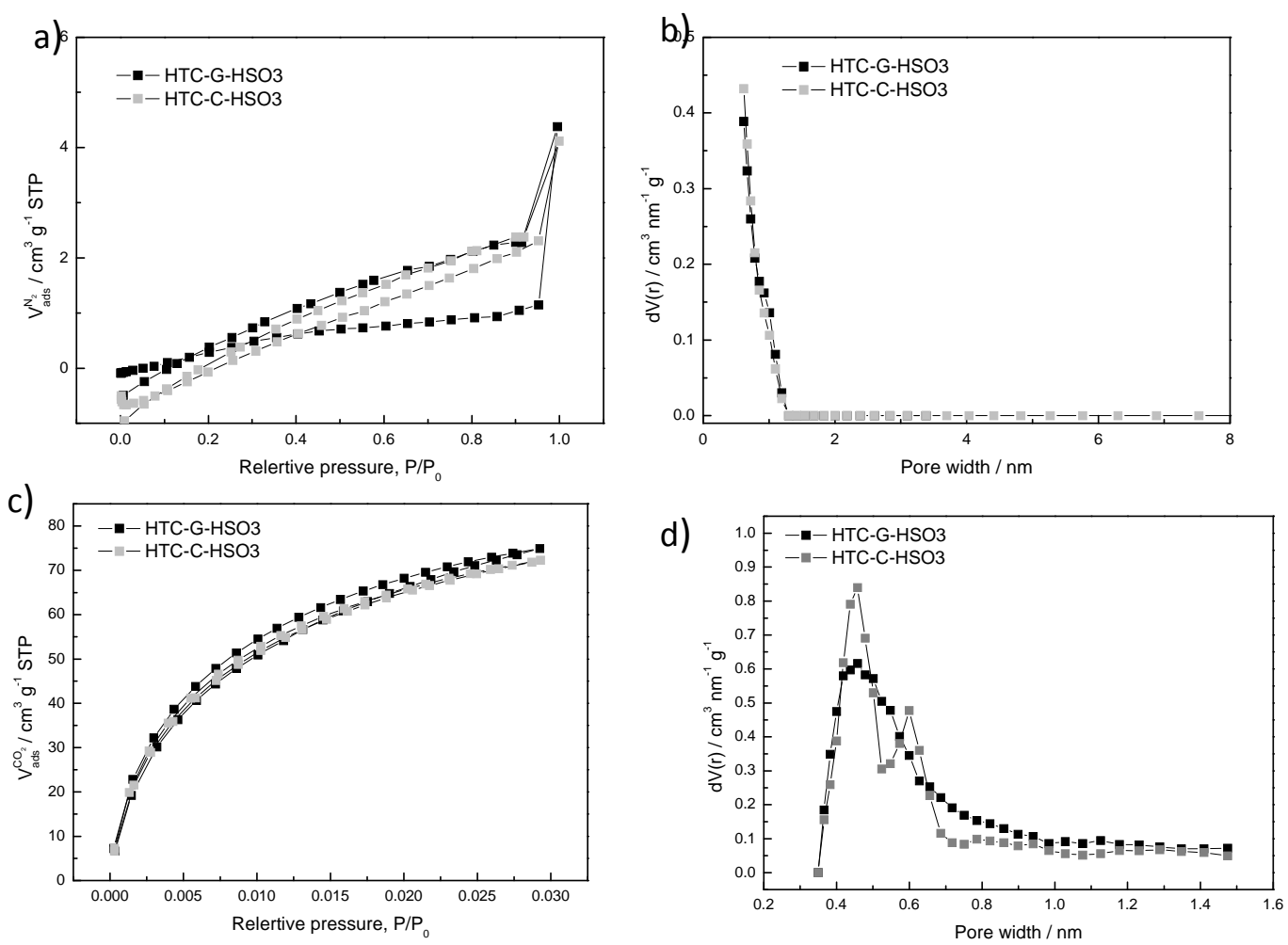

Fig. 5. (a) $\mathrm{N}_{2}$ adsorption of the sulfonated samples (cellulose and glucose) at $-196^{\circ} \mathrm{C}$. (b) Pore size distribution obtained using the NLDFT method for carbons from the $\mathrm{N}_{2}$ adsorption isotherms in (a). (c) $\mathrm{CO}_{2}$ adsorption isotherms for the sulfonated samples at $0{ }^{\circ} \mathrm{C}$. (d) Pore size distributions obtained using grand canonical Monte Carlo the from the $\mathrm{CO}_{2}$ adsorption isotherms.

als before sulfonation are very similar (result not shown here, please see ref. [22]). Since $\mathrm{N}_{2}$ is not a suitable gas to get precise informations on the pore structure of our catalysts, we have employed $\mathrm{CO}_{2}$ adsorption. The $\mathrm{CO}_{2}$ adsorption isotherms are shown in Fig. 5(c), while the corresponding pore size distributions in Fig. 5(d). The $\mathrm{CO}_{2}$ adsorption isotherms indicate good adsorption kinetics as compared to $\mathrm{N}_{2}$ adsorption and confirm the fact that the HTC materials are non-porous having only a very small fraction of micropores around and below $0.5 \mathrm{~nm}$. It can be thus concluded that for the catalytic activity, only the external surface of the materials containing sulfonated groups will be responsible as the pore volume and the pore size are too small to allow functionalization at the pore wall and diffusion of the reagent in the bulk. Our group is currently comparing the results obtained with non-porous catalysts with the ones obtained using mesoporous high-surface area sulfonated HTC materials.

\subsection{Conversion of levulinic acid into ethyl levlulinate}

Table 2 compares the conversion and selectivity of ethyl levulinate under various catalytic conditions. The experiments were repeated 3 times with very similar results. An average value was calculated. Despite the lack of porosity, the catalytic activity of sulfonated HTC-derived materials is similar to the one of pure sulphuric acid. This is impressive considering the relatively low surface area of our materials. We need to mention here that these results cannot be due to any leakage of sulphuric acid as we have carefully checked the $\mathrm{pH}$ before and after the catalytic reaction.

Furthermore we have performed elemental analysis as well as FT-IR after the catalytic reactions where we have not detected any change in elemental composition (or S) or the FT-IR spectra. Therefore we are absolutely sure that the catalytic activity is strictly related to the covalently bond $\mathrm{HSO}_{3}$ groups present on the surface of our materials or to a combination of $\mathrm{HSO}_{3}$ and other acidic groups present. As previously mentioned we are currently quantifying the presence of all surface groups on the HTC surface for a better understanding of their catalytic activity.

Highest results are obtained by using sulfonated HTC glucose. After $1 \mathrm{~h}$ at $60{ }^{\circ} \mathrm{C}$ the conversion is $91.5 \%$ and this increased to $97 \%$ after additional time $(3 \mathrm{~h})$. The selectivity of converting levulinic acid with ethanol into ethyl levulinate using $\mathrm{HTC}-\mathrm{G}-\mathrm{HSO}_{3}$ is $93 \%$ after $1 \mathrm{~h}$ and $97 \%$ after $3 \mathrm{~h}$. In the case

Table 2

Catalytic tests using $\mathrm{HTC}-\mathrm{HSO}_{3}$ heterogeneous catalyst as well as pure sulphuric acid homogenous catalysts.

\begin{tabular}{lccc}
\hline Catalyst & Time $(\mathrm{h})$ & Conversion (\%) & Selectivity (\%) \\
\hline HTC-Glu-S & 1 & 91.5 & 93 \\
HTC-Glu-S & 3 & 97 & 97 \\
HTC-Cell-S & 1 & 89.5 & 87.5 \\
HTC-Cell-S & 3 & 89 & 88.5 \\
HTC-RS-S & 1 & 61.1 & 39.4 \\
HTC-RS-S & 3 & 92.2 & 92.2 \\
Acid & 1 & 85.2 & 95.0 \\
Acid & 3 & 94.6 & 96.4 \\
No catalysts & 1 & 25 & 92 \\
\hline
\end{tabular}

Reaction conditions: EtOH/Acid $=5: 1,60^{\circ} \mathrm{C}$ 
of sulphonated HTC cellulose materials both the conversion and the selectivity are lower then for glucose-derived materials both after 1 and $3 \mathrm{~h}$. However it is interesting to notice that there are no major differences in both values after 3 or $6 \mathrm{~h}$, which means that the maximum conversion is reached after $1 \mathrm{~h}$ with no major changes. This is the opposite case for the rye straw derived material where the conversion and selectivity are the lowest after $1 \mathrm{~h}$ (61.1\% and 39.4\%, respectively) and increase to $92.2 \%$ for both after $3 \mathrm{~h}$ which is close to that obtained for glucose. These differences can be related to the difference in morphologies and accessible surface containing sulfonic groups between rye straw and glucose. As mentioned before, these materials are non-porous and only the external surface will play here a role.

The conversion and selectivity obtained using sulphuric acid as a homogenous catalyst are close to the ones obtained with both glucose derived materials or rye straw after $3 \mathrm{~h}$. Interesting, the conversion obtained with glucose after $1 \mathrm{~h}$ is higher then the one obtained with the homogenous acid catalyst. These differences could related to the different concentration of sulfonic groups taken part in the catalytic reaction as we did not yet quantified the amount of sulfonic groups in order to have similar conditions in both homogenous and heterogeneous catalysis reactions. Finally, compared with other literature results where ethyl levulinates were obtained using heterogeneous acid catalysts, it is clear that sulfonated HTC carbons can obtain higher conversion of levulinic acid into ethyl levulinate. Teixeira da Silva et al. [24] studied the use and the activities of different zeolites (HUSY, HBEA, HMOR, HZSM-5, HMCM-22) and sulfated oxides $\left(\mathrm{SnO}_{2}, \mathrm{ZrO}_{2}, \mathrm{Nb}_{2} \mathrm{O}_{5}, \mathrm{TiO}_{2}\right)$ to that presented by a commercial sulfonic resin (Amberlyst-15) in the esterifica- tion of levulinic acid with ethanol. The highest conversion was obtained by Amberlyst-15 (54\%), even after 5 runs of reactions. Bokade et al. [25] also referred the 95.5\% conversion of levulinic acid to ethyl levulinate catalysed by H-ZSM-5. Yan et al. [11] have also recently obtained good catalytic activity for the production of methyl and ethyl levulinates over mesoporous $\mathrm{H}_{4} \mathrm{SiW}_{12} \mathrm{O}_{40}-\mathrm{SiO}_{2}$ catalysts $(73 \%$ yield of methyl levulinate and $67 \%$ yield of ethyl levulinate) but using a large excess of catalyst.

\section{Conclusions}

We have reported for the first time the use of biomass-derived hydrothermal carbons modified with sulfonic groups as heterogeneous catalysts for concerting levulinic acid to ethyl levulinates. Both the selectivity and conversions were excellent at $60{ }^{\circ} \mathrm{C}$ for all three biomass derivatives, with glucose exhibiting the best results. Comparing our results with homogenous sulphuric acid as well as other literature data, we can clearly state that HTC materials are excellent candidates for heterogeneous catalytic applications in the filed of biomass conversion. Given the fact that they are themselves biomass-derived this is highly advantageous in terms of future bio-refineries as well as future chemical industries based completely on abundant and renewable chemicals and catalysts. The catalysts are recyclable and of low cost, environmentally friendly in terms of both their production as well as end of life. In the future we plan to use the HTC materials to convert the biomass-derived levulinic acid remaining in the water phase after the HTC process. This will bring further value to this technology and will increase the overall biomass conversion during this process.

\section{Graphical Abstract}

Chin. J. Catal., 2014, 35: 929-936 doi: 10.1016/S1872-2067(14)60125-X

Esterification of levulinic acid into ethyl levulinate catalysed by sulfonated hydrothermal carbons

Filoklis D. Pileidis, Maham Tabassum, Sam Coutts, Maria-Magdalena Titirici*

Queen Mary University of London, United Kingdom

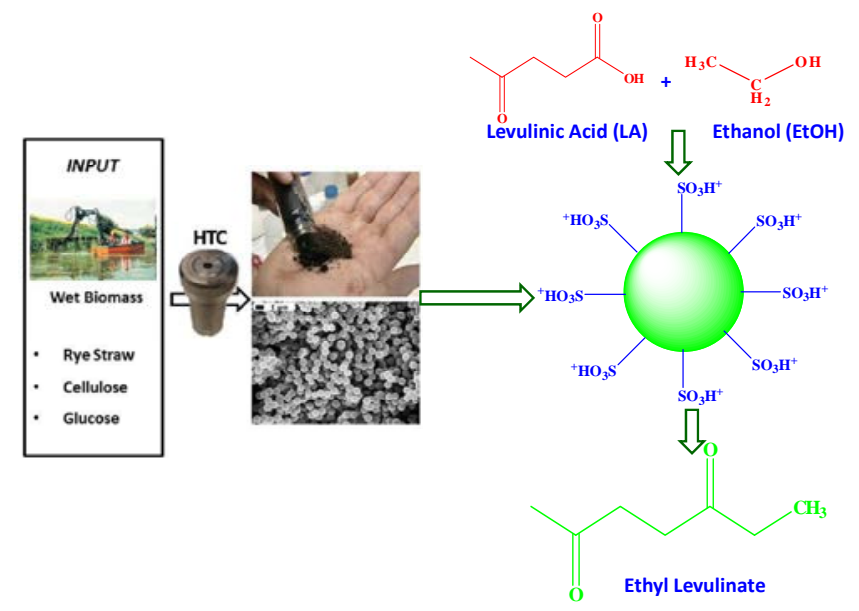

Ethyl levulinates are very important biodiesel additives. This paper presents the synthesis of ethyl levulinates derived from biomass using biomass derived materials as solid catalysts. 


\section{References}

[1] Clark J H. Acc Chem Res, 2002, 35: 791

[2] Knothe G, Van Gerpen J, Krahl J. The Biodiesel Handbook; Champaign, Illinois: AOCS Press, 2005. 173

[3] Hayes D J, Fitzpatrick S W, Hayes M H B, Ross J R H. In: Kamm B, Gruber P R, Kamm M ed. Biorefineries Industrial Processes and Product, Weinheim: Wiley-VCH,2005. 139

[4] Joshi H, Moser B R, Toler J, Smith W F Walker T. Biomass Bioenergy, 2011, 35: 3262

[5] Windom B C, Lovestead T M, Mascal M, Nikitin E B, Bruno T J. Energy Fuels, 2011, 25: 1878

[6] Bankole K S. Thesis: Uncatalysed Esterifoication of Biomass-Derived Carboxylic Acids, University of Iowa, 2011

[7] Bart H J, Reidetschlager J, Schatka K, Lehmann A. Ind Eng Chem Res, 1994, 33: 21

[8] Garves K. Wood J Chem Technol, 1988, 8: 121

[9] Olson E S, Kielden M R, Schlag A J, Sharma R K. ACS Symp Ser, 2001, 784: 51

[10] Dharne S, Bokade V V. J Nat Gas Chem, 2011, 20: 18

[11] Yan K, Wu G, Wen J, Chen A. Catal Commun, 2013, 34: 58

[12] Pasquale G, Vazquez P, Romanelli G, Baronetti G. Catal Commun, 2012, 18: 115
[13] Budarin V L, Clark J H, Luque R, Macquarrie D J. Chem Commun, 2007: 634

[14] Macia-Agullo J A, Sevilla M, Diez M A, Fuertes A B. ChemSusChem, 2010, 3: 1352

[15] Zhang B, Ren J, Liu X, Guo Y, Guo Y, Lu G, Wang Y. Catal Commun, 2010, 11: 629

[16] Titirici M M, White R J, Falco C, Sevilla M. Energy Environ Sci, 2012, 5: 6796

[17] Titirici M M, Thomas A, Antonietti M. J Mater Chem, 2007, 17: 3412

[18] Cakan R D, Titirici M M, Antonietti M, Cui G, Maier J, Hu Y S. Chem Commun, 2008: 3759

[19] Baccile N, Laurent G, Babonneau F, Fayon F, Titirici M M, Antonietti M. J Phys Chem C, 2009, 113: 9644

[20] Falco C, Baccile N, Titirici M M. Green Chem, 2011, 13: 3273

[21] Schuhmacher J P, Huntjens F J, van Krevelen D W. Fuel, 1960, 39: 223

[22] Socrates G. Infrared and Raman Characteristic Group Frequencies, 3rd Ed. New York: Wiley, 2005. 211

[23] Yu L, Falco C, Weber J, White R J, Howe J Y, Titirici M M. Langmuir, 2012, 28: 12373

[24] Fernandes D R, Rocha A S, Mai E F, Mota C J A, Teixeira da Silva V. Appl Catal A, 2012, 425-426: 199

[25] Nandiwale K Y, Niphadkar P S, Deshpande S S, Bokade V V. J Chem Technol Biotechnol, DOI: 10.1002/jctb.4228 